\title{
EEN VERLOREN COLLECTIE HERINNERD: \\ DE VERZAMELING VAN MR.DR. VAN BUTTINGHA WICHERS
}

\section{Inleiding}

Lieve Jetteke, [...] Van ons porcelein en schilderijen zullen we niet veel terugzien: althans de garage is leeg \& een naam adres ligt er niet in doch van veel belang is deze zaak niet; iedereen laat veeren. ${ }^{1}$

Zo schreef mr.dr. Gerard Gilles van Buttingha Wichers (I879-I945) vanuit het St. Vincentius kamphospitaal te Batavia (het huidige Jakarta) op 22 september 1945 aan zijn dochter. Hij hoopte de verjaardagen van de kinderen op 27 november met elkaar te kunnen vieren. Het zou er niet meer van komen. Op I7 november I945 overleed hij, verzwakt door langdurige gevangenschap, herenigd met zijn gezin in het interneringskamp Kramat. Van Buttingha Wichers' omvangrijke collectie porselein, 'Compagniesmeubilair', hindoe-Javaanse en Europese kunst en antiek was verloren gegaan; deels achtergebleven, deels verkocht, deels gestolen, maar gebleven in de herinnering en als zodanig levend.

De manier waarop er verzameld werd, wat en waarom, welke betekenis aan objecten en de collectie toegekend werd en hoe de collectie werd samengesteld en geëtaleerd, hangen nauw samen met de manier waarop de wereld op dat moment aanschouwd, benaderd en geordend werd. Wat vertelt Van Buttingha Wichers' bijzondere collectie - vooral overgeleverd door foto's en bewaarde stukken - ons over hem, over de betekenis van de collectie en wat vertelt zijn collectie ons over de koloniale samenleving aan de vooravond van de Tweede Wereldoorlog?

\section{Verzamelen in Batavia rond 1935}

Van Buttingha Wichers werd omschreven als een man voor wie men ontzag had, een man die los stond van de waan van de dag, onafhankelijk en met gevoel voor stijl en traditie, bonhomie uitstralend. ${ }^{2} \mathrm{Na}$ een carrière bij De Nederlandsche Bank ging hij in 1929 naar Nederlands-Indië en werd in hetzelfde jaar benoemd tot president van De Javasche Bank ('the bankers bank') in Batavia als opvolger van mr. L.J.A. Trip (I876-I947).

Hij woonde met zijn vrouw Heleen van Buttingha Wichers-Laman de Vries (I894-I966) en hun twee kinderen Jettie en Gerard in de ambtswoning aan het Koningsplein Zuid 6, het huidige Medan Merdeka. Van Buttingha Wichers' culturele, historische en wetenschappelijke belangstelling leidden ook tot sociale functies als het vicevoorzitterschap van het Koninklijk Bataviaasch Genootschap van Kunsten en Wetenschappen, lid van het college van curatoren van de Nederlandsch-Indische Sterrenkundige Vereeniging en lid van het bestuur van het Algemeen Nederlandsch 
Afb. za $^{2}$

Het gevolg met pusaka van de sultan van

Yogyakarta Hamengku Buwono VIII, wachtend op de voorgalerij, oktober 1939

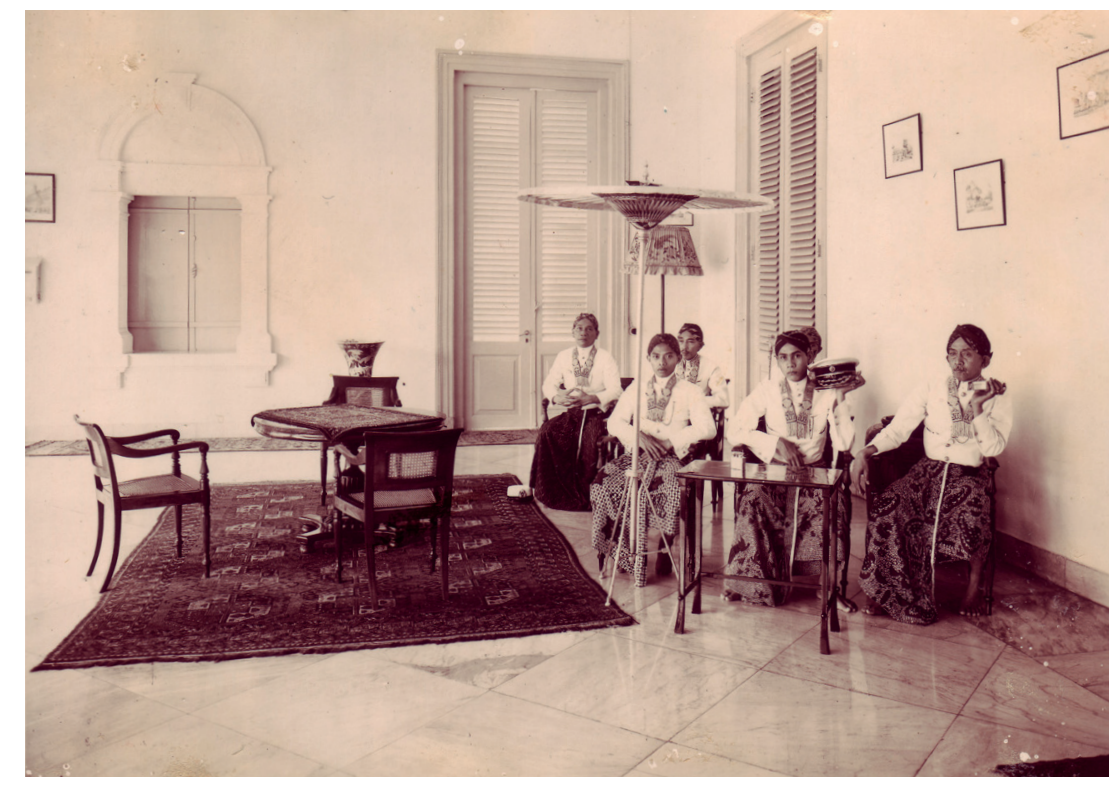

Afb. 3b $^{\text {b }}$

Ontvangst van de sultan van Yogyakarta Hamengku Buwono VIII in de binnengalerij door Van Buttingha Wichers en zijn vrouw, oktober 1939

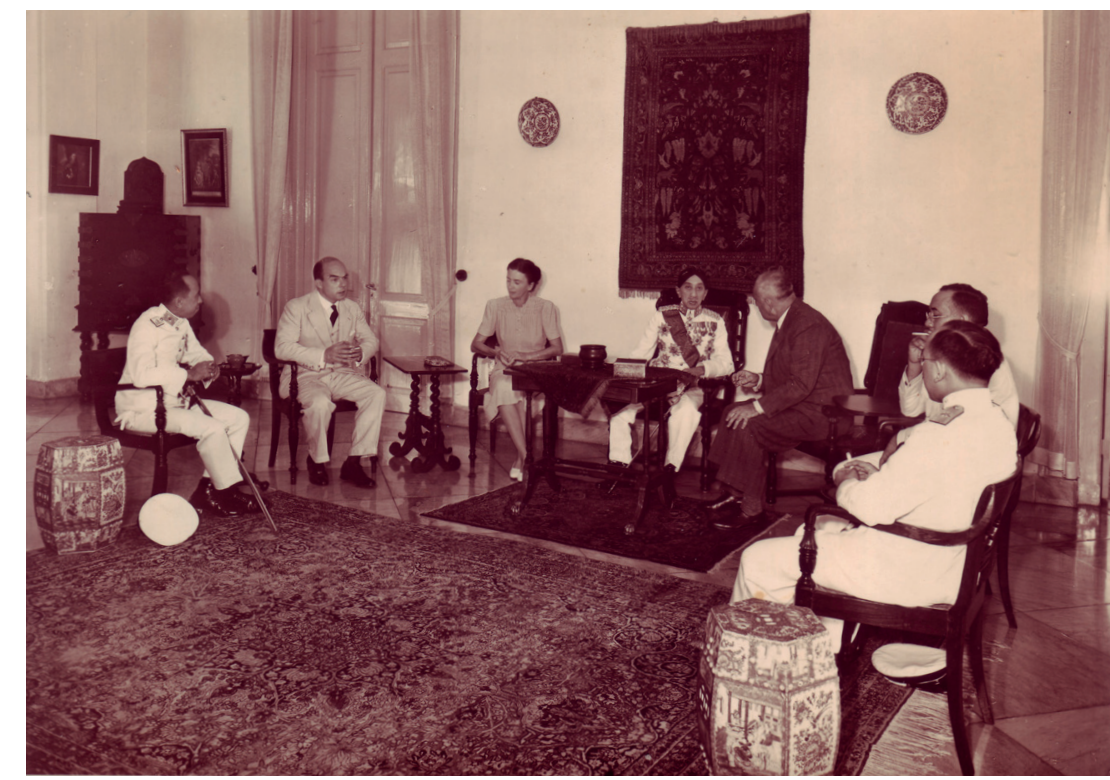

zich in dergelijke verenigingen en genootschappen had verzameld. ${ }^{4}$ Van Buttingha Wichers' belangstelling voor het verleden en de kunsten leidde ook tot het samenstellen van een grote, gevarieerde verzameling met een nadruk op porselein. De geschiedenis van deze collectie is grotendeels gebaseerd op de verhalen van zijn dochter Jettie de la Hayzevan Buttingha Wichers (I929-2013), bewaard gebleven foto's en de enkele stukken die het gezin het kamp in heeft kunnen meenemen.

De foto's zijn gemaakt tussen 1929 en 1942 door de Oudheidkundige Dienst in Indië en door professionele fotografen als Bongenaar, Van der Kolk en Oeij Eng Tian. 5 Ze geven een beeld van het huis, de inrichting, de verzameling, het gezin en het sociale milieu waarin Van Buttingha Wichers $2: 39: 46 \mathrm{pM}$ 
zich in die jaren bewoog. Het is het leven van de top van de Europese koloniale elite: officiële diners en ontvangsten met de gouverneurgeneraal, hooggeplaatste ambtenaren en Javaanse leiders als de sultan van Yogyakarta Hamengku Buwono VIII (I880-I939) en zijn gevolg (afb. 3a en 3b) en meer huiselijke diners met vrienden uit de top van het bestuur, de bankwereld, handel en industrie. De foto's tonen een voornaam koloniaal huis met porseleinen beelden, borden, kommen en schalen uitgestald in antieke kasten, aan de muur, in wandrekken, op tafels en op de grond. We zien schilderijen, glazen bokalen, grote wandkleden en Rafflesstoelen (afb. 4). Hindoe-Javaanse godenbeeldjes, op grotere schaal in NederlandsIndië sinds de Java-oorlog (I825-I830) door Europeanen verzameld, stonden bij Van Buttingha Wichers gebroederlijk naast het porselein in en op de kasten en tafels. Er was voorts een hoekje gecreëerd met zogenaamde $\mathrm{I} 7^{\mathrm{e}}$ - of $\mathrm{i} 8^{\mathrm{e}}$-eeuwse 'Molukse stoelen' (afb. II), prachtig gebeeldhouwde grote en kleine kasten en guéridons (eenpootstafeltjes).

In de collectie lag het accent op deze 'Compagniesmeubelen' en het porselein. 'Zijn verzameling van oud-Indische meubelen uit de

Afb. 4

Binnengalerij $(8 \mathrm{x}$ $24 \mathrm{~m}$ ) gefotografeerd vanuit de eetkamer. De pronkkast (links op de foto) bevat zilver en glas
Compagniestijd en oud porselein had zijn hart', schreef Van Buttingha Wichers' afdelingschef in diens In Memoriam. ${ }^{6}$ Dit 'Compagniesmeubilair' werd door Van Buttingha Wichers en anderen vanaf de eeuwwisseling verzameld als herinnering aan de 'grootse daden' van de Hollanders die in de $17^{\mathrm{e}}$ en $18^{\mathrm{e}}$ eeuw met de VOC naar Azië zeilden en als de wegbereiders van het $\mathrm{I}^{\mathrm{e}}{ }^{\mathrm{e}}$-eeuwse koloniale rijk werden gezien.

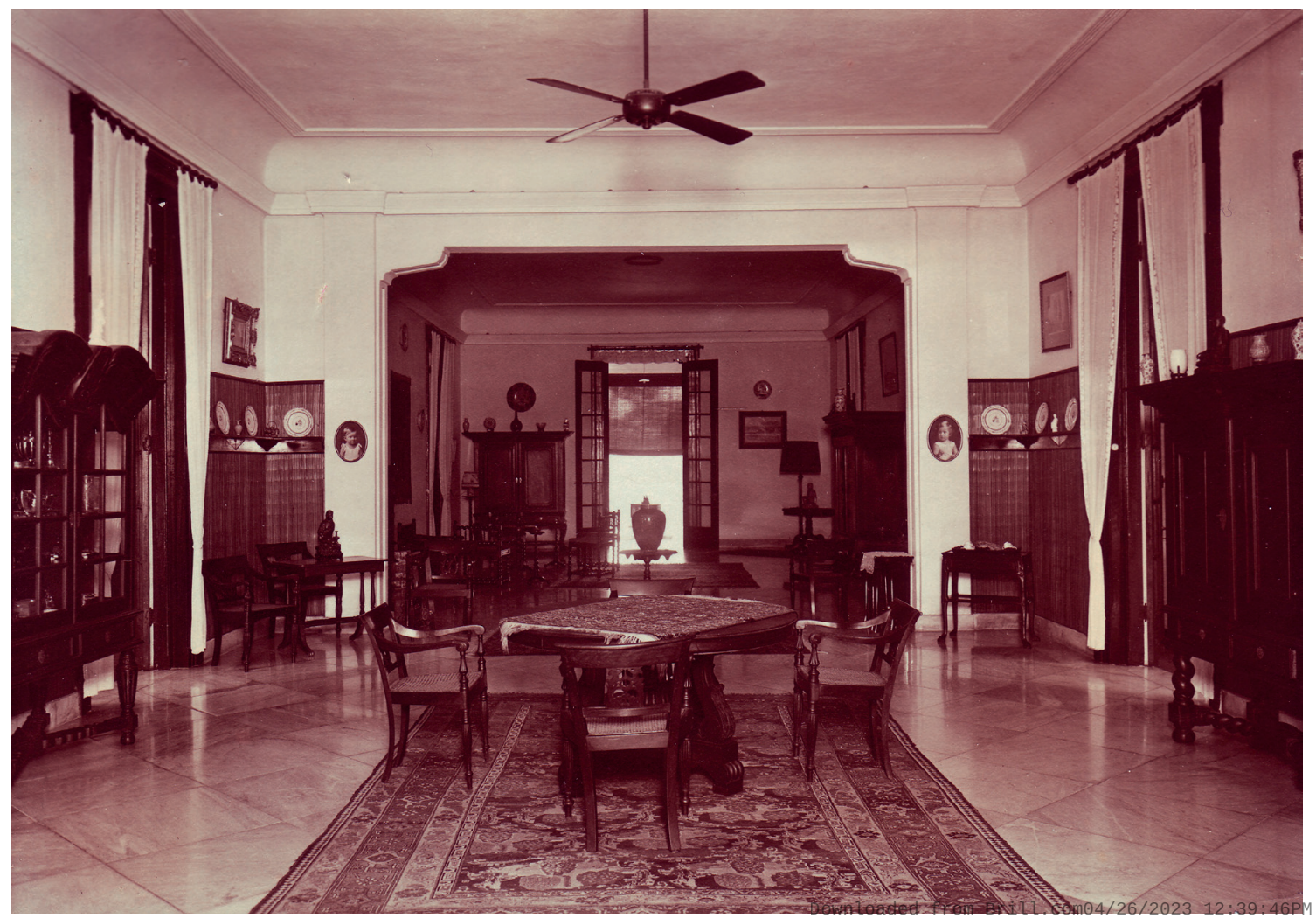



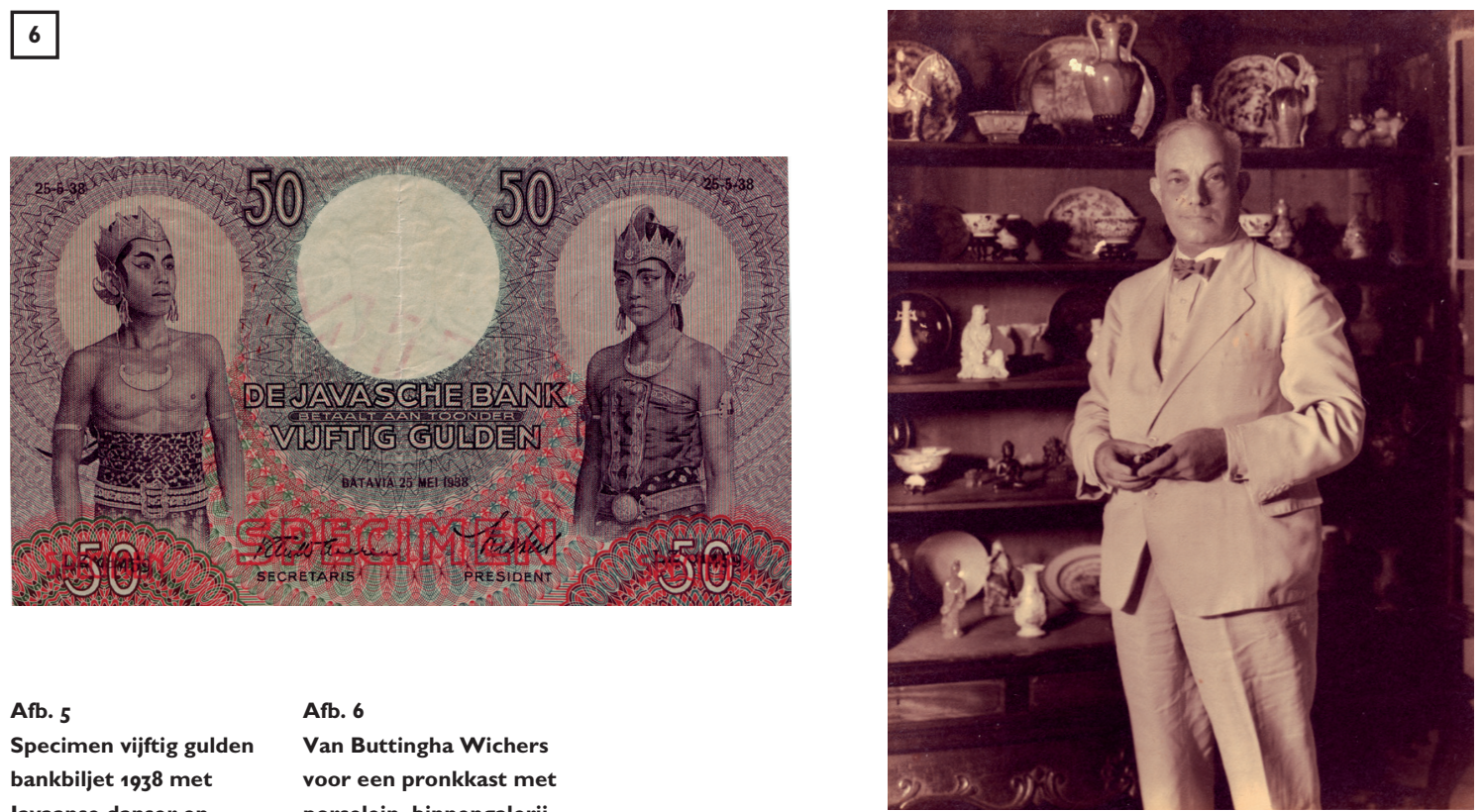

Afb. 6

Van Buttingha Wichers voor een pronkkast met porselein, binnengalerij
Afb. 7 (pag. 7) Pronkkast met porselein, binnengalerij
Zijn belangstelling voor de Compagniestijd zien we terug in zijn aandeel bij de oprichting en financiering van Museum Oud Batavia in het oude, historische centrum. Dat museum diende '[ter] vermeerdering der kennis van, zoowel als de bevordering der belangstelling voor het OudHollandsche verleden van Batavia'. ${ }^{7}$ We zien het ook in zijn bijdrage aan het goede verloop van de zoektocht naar het graf van Jan Pieterszn. Coen (1587-I629), die toen gezien werd als dé stichter van Batavia en het Nederlandse koloniale rijk. Van Buttingha Wichers presenteerde zich met deze activiteiten, zijn bestuurstaken en collectie als een 'vaderlandslievende' Nederlander in de kolonie. Tegelijkertijd had hij oog voor de Javaanse cultuur. Hierin past zijn trots op de in I938 en I939, op zijn initiatief, afgebeelde Javaanse hofdansers op de nieuwe bankbiljetten (afb. 5): een breuk met eerdere biljetten waarop 'vaderlandse helden' als Coen prijkten. ${ }^{8}$

Een bijzondere liefde had Van Buttingha Wichers voor Chinees porselein. Niet voor niets liet hij zich voor een van zijn pronkkasten portretteren: het gezicht half serieus, half vrolijk naar de fotograaf gericht, in zijn handen een collectiestuk (afb. 6). We zien op de foto's dat ruim I50 van de porseleinen voorwerpen zorgvuldig uitgestald en gepresenteerd waren in pronkkasten (afb. 7 en 8). Daarbij valt op dat hij nadrukkelijk aandacht had voor pre-Qing Chinese keramiek. Een derde deel van de stukken in de pronkkasten vond zijn oorsprong in de Tang- (6I8-907), Song- (960-I279) en Ming-dynastie (I368-I644). Dat is bijzonder, want pas heel aarzelend kwam er in de jaren 1920 zowel in Indië als in Europa belangstelling voor het pre-Qing porselein. In de meeste Europese collecties bleef de nadruk liggen op porselein uit de Qing-periode (I644-I9II). Wellicht liet Van Buttingha Wichers dergelijke keramiek deels rechtstreeks uit China

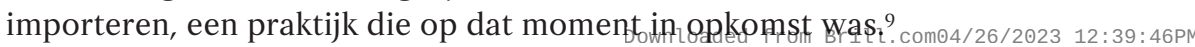




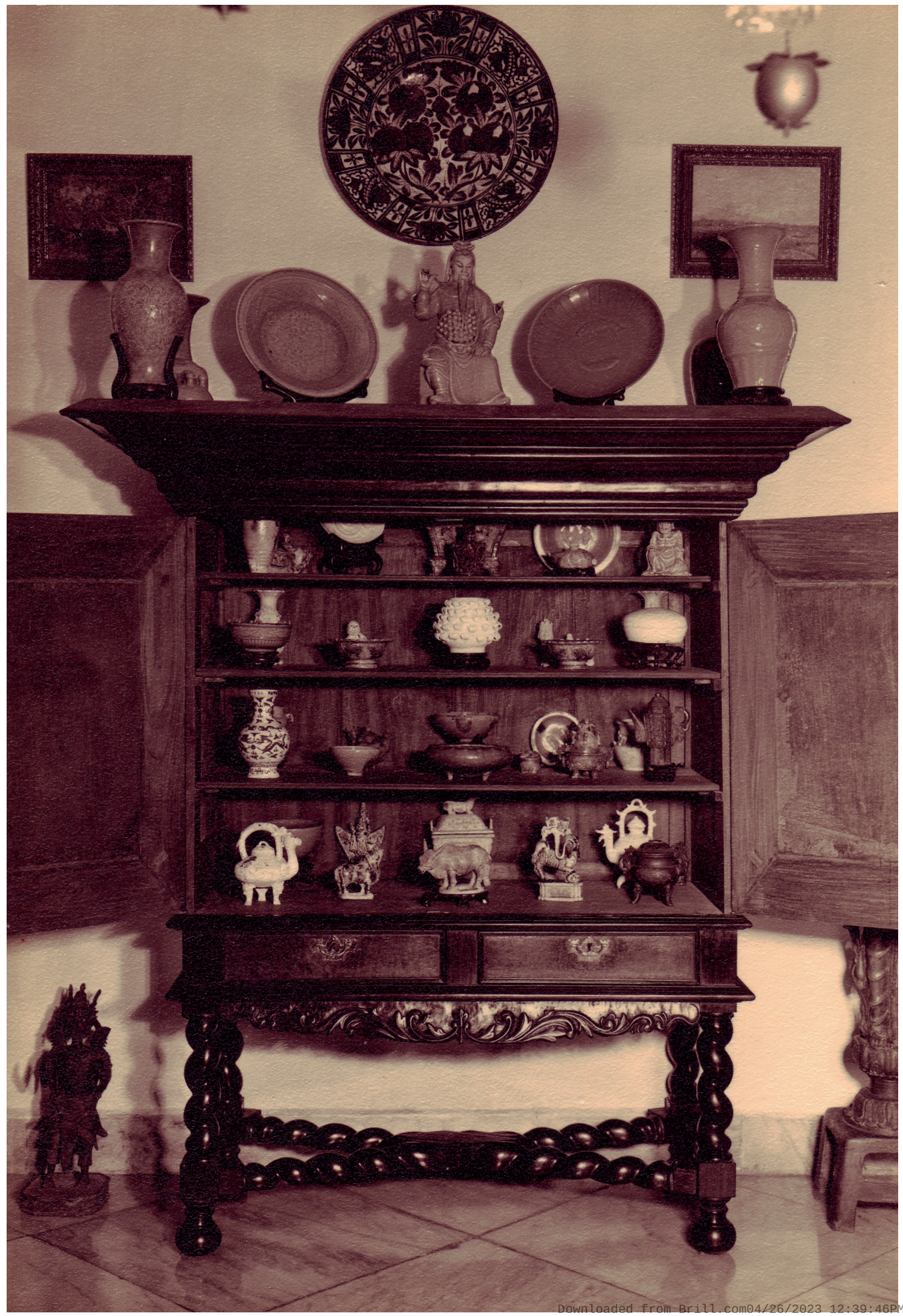




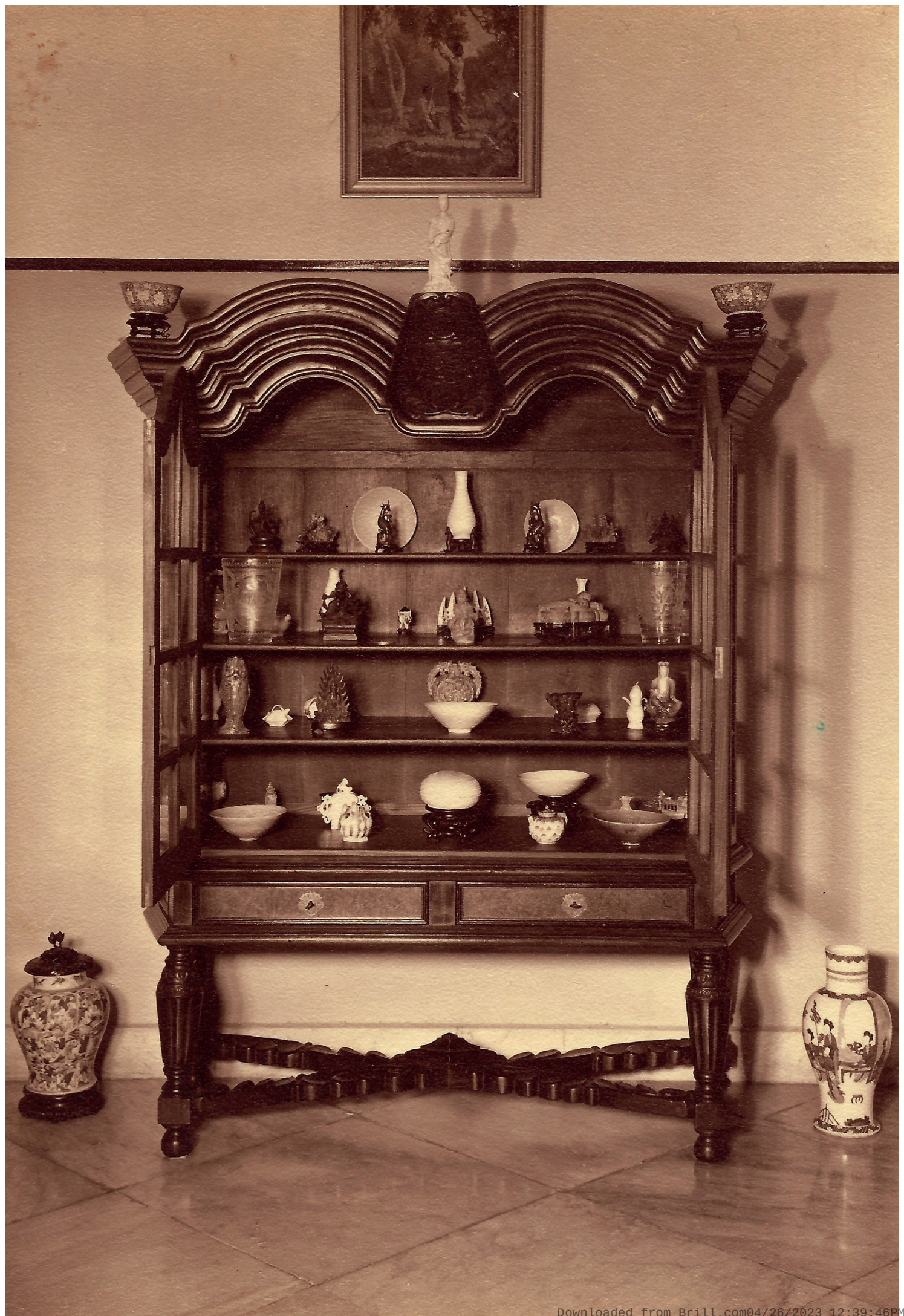


Afb. 8

Pronkkast met

porselein, binnengalerij
Chinees porselein werd van oudsher in de Indonesische archipel gevonden in vooral Batavia, West-Java, op de Zuidelijke Molukken, Zuid-Sulawesi en Noord- en Midden-Sumatra. Er bestonden namelijk vanaf de Song-dynastie nauwe handelsrelaties met het Chinese rijk. Het grove swatow uit de Mingperiode, met blauwgrijs glazuur en blauwe beschilderingen, werd zelfs een statussymbool voor heersers in Zuidoost-Azië. ${ }^{\text {Io }}$

Europeanen kregen pas aan het einde van de $19^{\mathrm{e}}$ eeuw echt belangstelling voor porselein en rond 1900 raakte het verzamelen van porselein alsook van VOC-meubilair zelfs in de mode: 'Zij doet tegenwoordig in Compagnies meubilair en oud blauw [porcelein], omdat dat zoo mode is. Om nieuw te zijn verzamelt zij oud', schreef bestuursambtenaar Henri Damsté (I874-I955) in I904 over een Europese verzamelaarster in Batavia." Controleur-gezaghebber Friedrich W. Stammeshaus (I88I-I957), die vanaf I929 als toezichthouder en later als conservator van het Atjeh Museum in Banda Aceh (het vroegere Kota Radja) werkte, schreef:

Iedereen die in Atjèh komt doet aan het verzamelen van Atjèhsche borden (pinggan Atjèh) [uit China] en velen betalen te hooge prijzen voor soms minderwaardige exemplaren. [...] Ontegenzeggelijk vormen de "Atjèhsche borden" een zeer mooie wandversiering en door het zien van een mooie collectie komt men al spoedig in de verleiding om ook aan deze "sport" mee te doen! $!^{2}$

Het waren vooral 'notabelen'13 die verder gingen dan de enkele borden aan de muur en die grote collecties Chinees porselein aanlegden. Dat is niet verwonderlijk, want het verzamelen van porselein was een prijzige aangelegenheid.

Een reden dat er juist in de jaren vlak voor de Tweede Wereldoorlog zo veel, ook ouder, porselein werd verzameld, kan men vermoedelijk vinden in de wereldwijde crisis van de jaren 30. De lokale bevolking leed onder hoge prijzen en grote werkeloosheid. Het is niet verwonderlijk dat juist op dat moment veel oude erfstukken (pusaka), die eerder door de lokale bevolking in familiebezit gekoesterd werden, op de markt kwamen. De bevolking kon die inkomsten goed gebruiken. Ondanks dit toenemende aanbod bleven de prijzen van het porselein omhoog gaan, vermoedelijk omdat de vraag onder Europeanen groot was. We zien dan dat de lokale bevolking actief op zoek ging naar verhandelbaar erfgoed. In Sulawesi werden graven geschonden waarin zich porseleinen urnen bevonden. In Aceh werden massaal borden opgekocht door lokale handelaars ('bordenjagers') die ze naar de grote steden brachten waar ze met 'een zoet winstje' doorverkocht werden aan een tussenhandelaar of aan Europeanen die bang waren achter het net te vissen. ${ }^{14}$ Er werden zelfs vervalsingen gemaakt om te verkopen. ${ }^{15}$

Kortom, porseleinen erfstukken die de lokale bevolking rond I9oo niet wenste te verkopen, kwamen in de loop van de jaren 30 'eerst goed los' en dat is te zien in het diverse karakter en de omvang van Van Buttingha Wichers' collectie. ${ }^{6}$ De conservator porselein van het Bataviaasch Genootschap, Egbert W. van Orsoy de Flines (I886-I964) schreef in I95I: 'het wordt steeds duidelijker, dat tot voor kort nog altijd de belangrijkste stukken [...] zijn achtergehouden' ${ }^{17}$ De keuze voor een woord als 'achterhouden' (en later spreekt hij ook van niet willen 'loslaten')

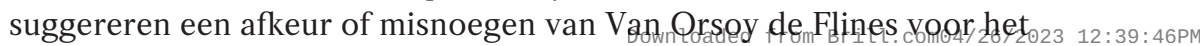


in bezit houden van belangrijke kunstvoorwerpen. Het kan wellicht als tekenend gezien worden voor het onbegrip en de afstand die er bestond tussen een groot deel van de Europese koloniale elite en de cultuur van de lokale bevolking rond 1930.

Die afstand was ook vrij letterlijk: Europese verzamelaars waren voor hun collectiestukken vooral afhankelijk van aan huis komende tussenhandelaren (de zogenaamde kelontongs of langganans). Herkomst is nu dan ook veelal moeilijk te achterhalen. Dit geldt ook voor Van Buttingha Wichers' aankopen. Volgens de overlevering was hij geen afdinger; de handelaars zouden bij hem als eerste langs gekomen zijn om pas daarna naar anderen te gaan waar een minder goede prijs te behalen was. Van Buttingha Wichers zou hierdoor de mooiere voorwerpen hebben kunnen verwerven. ${ }^{8}$ Dat was echter geen garantie. De kwaliteit van zijn stukken is lastig te duiden en lijkt wisselend. 'Dit is een beruchte fake', heeft zijn vrouw als commentaar achterop een foto van een betaalmeesterkastje geschreven. ${ }^{19}$ Interessant is het om te bedenken dat wat er verzameld werd door Europeanen in Indië dus voor een aanzienlijk deel bepaald werd door het aanbod van deze handelaren, die weer op hun beurt afhankelijk waren van de lokale bevolking - groepen mensen die in de geschiedenis vaak vergeten worden.

Afb. 9

Tukang-tukang antik met in doeken de handelswaar, achterkant van de ambtswoning, begin jaren 1930

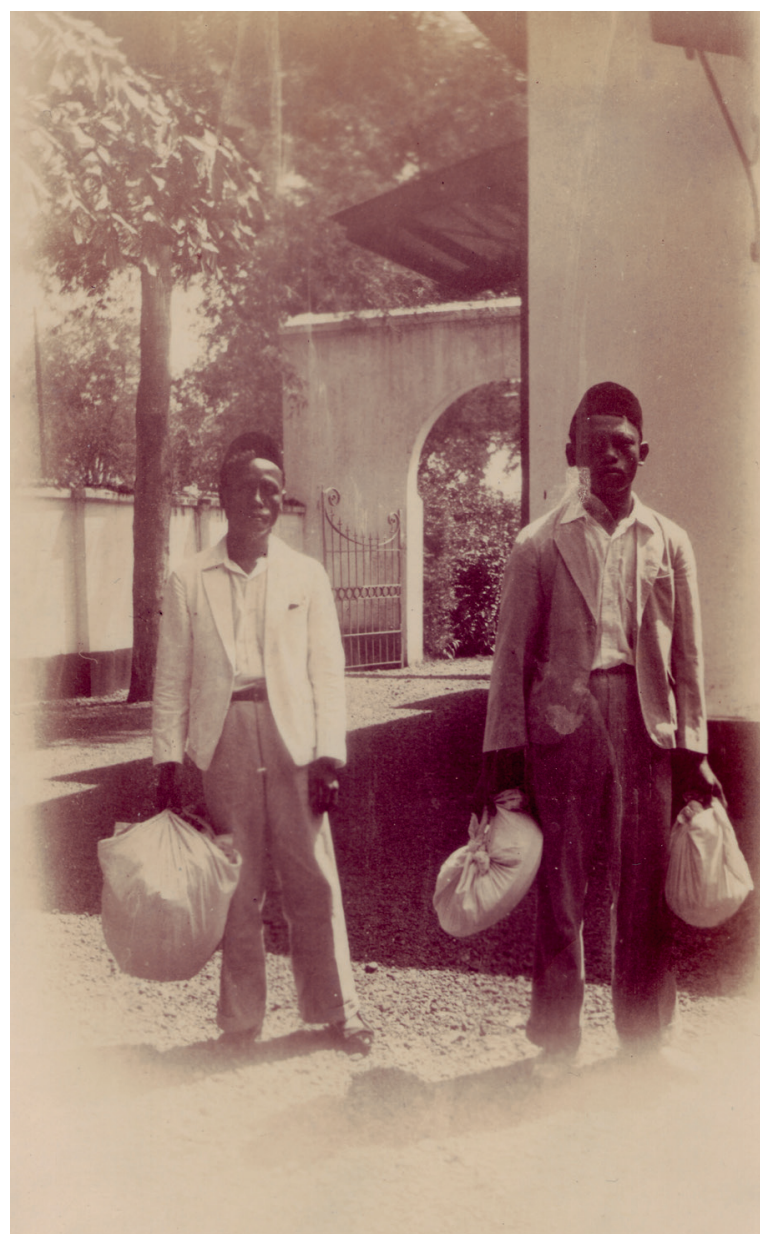


Gezicht en naam van deze mensen zijn nauwelijks bekend. Daarom is het bijzonder dat Van Buttingha Wichers een foto en een film heeft genomen van de handelaren (tukang-tukang antik) van wie hij objecten kocht. Op de foto dragen beide handelaren stukken in doeken gewikkeld (afb. 9). De film toont een ontspannen gesprek tussen Van Buttingha Wichers en een tukang antik. De aanwezigheid van deze beelden tussen de andere foto's en films zegt iets over de belangrijke rol die de tukang-tukang antik in de vorming van Van Buttingha Wichers' collectie innamen.

De foto's van de collectie laten verder de manier zien waarop hij door de jaren heen zijn collectie tentoonstelde. Hoewel verzamelen een privéaangelegenheid is, is het onlosmakelijk verbonden met het bestendigen of vormen van iemands eigen publieke identiteit. ${ }^{20} \mathrm{De}$ uitgestalde meubelen, porselein en schilderijen dienden om gezien te worden. Wisselende opstellingen konden de aandacht trekken van terugkerende gasten. Met veel plezier leidde Van Buttingha Wichers hen rond. Zijn afdelingschef schreef:

Zoo werd ik kort na mijn aankomst te Batavia bij de familie Wichers ten eten uitgenodigd. De avond is mij altijd bijgebleven: het oud-Indisch huis aan het Koningsplein met zijn ruime kamers, de Heer Wichers als gastheer ons in den loop van den avond den trots en de liefde van den verzamelaar zijn antiek, zijn porselein toonende. ${ }^{21}$

Hiermee stond Van Buttingha Wichers in een verzameltraditie die in de eerste decennia van de $20^{\mathrm{e}}$ eeuw in Java, in Batavia, maar ook elders in de archipel, zichtbaar werd. Verzamelen was, behalve een aangenaam tijdverdrijf, door het etaleren van je goede, Europese smaak en exclusiviteit onlosmakelijk verbonden met sociale klasse en status.

\section{Een collectie verloren: de oorlog}

Dat Van Buttingha Wichers veel foto's liet maken van zijn collectie is veelzeggend: ze waren vermoedelijk onderdeel van een te maken catalogus van zijn geliefde collectie waarmee zijn verzameling ook voor het grote publiek zichtbaar en aan zijn naam verbonden zou worden. ${ }^{22}$ Als voorbeeld zag hij het beroemde boek van de verzameling van Sir Percival David door R.L. Hobson. Dat was in 1934 verschenen en daarvan had hij een exemplaar, nummer 254, in zijn bezit.

Van Buttingha Wichers' ambitieuze plannen werden echter doorkruist door de inval van de Japanners in 1942. De dreiging hing al even in de lucht. In het najaar van 1939 had Van Buttingha Wichers als cultuurliefhebber het Museum van het Bataviaasch Genootschap ruimte in de 'Oorlogskluis' in Bandung beschikbaar gesteld voor hun kostbaarste voorwerpen. ${ }^{23}$ In diezelfde kluis had hij ook zijn eigen sieraden, glaswerk en zilver ondergebracht. ${ }^{24}$ Zijn porselein, hindoe-Javaanse kunstvoorwerpen en schilderijen sloeg hij op in een garage, terwijl de meubels in het huis aan het Koningsplein bleven staan.

Het hoofdkantoor van De Javasche Bank werd verplaatst naar Bandung en begin 1942 volgde Van Buttingha Wichers. Zijn vrouw en jonge kinderen wees hij bij zijn afscheid op een kluis en zijn vrouw gaf hij ter bescherming een revolver mee. ${ }^{25}$ Ondertussen begonnen de Japanners de samenleving te ontdoen van haar 'Westerse elementen'. Dola een huisarrest in Bandung 12:39:46PM 


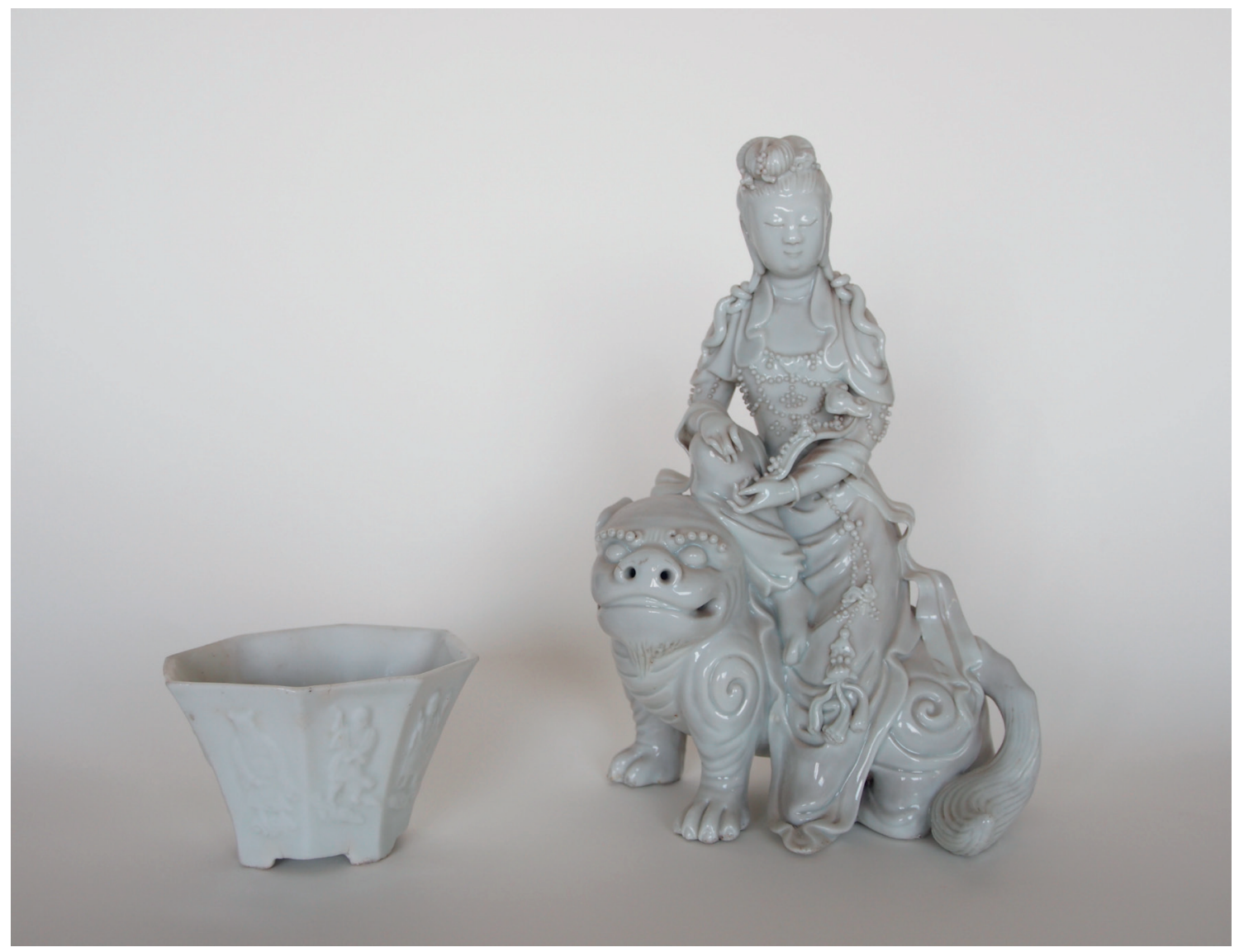

Afb. 10

Blanc de Chine plengofferbekertje en Guanyin (gezeten op een leeuw) werd Van Buttingha Wichers op 27 maart 1942 door de Kempeitai, de Japanse militaire politie, gevangengenomen. Zijn gezin in Batavia trof niet veel later hetzelfde lot. Ze kregen een dag om hun hutkoffer te pakken en het huis te verlaten. Opvallend genoeg namen ze een blanc de Chine Guanyinbeeldje en een achthoekig plengofferbekertje met de acht onsterfelijken mee (afb. Io), en een vaasje, ook blanc de Chine. ${ }^{26}$ Daarnaast was er ruimte voor enkele boeken over porselein, zoals het indertijd 'bekende boek van Kleykamp', ${ }^{27}$ en het boek over de befaamde collectie van Sir Percival David. Tevens lijkt het erop dat zij wat meubels, zoals het betaalmeesterkastje, naar het (eerste) kamp Kramat mee konden nemen. ${ }^{28}$ Het is opmerkelijk dat de vrouw en kinderen van Van Buttingha Wichers juist deze zaken uitkozen en van kamp naar kamp meetorsten: was het porselein een aandenken aan hun echtgenoot en vader? Was het meegenomen met het oog op zijn terugkomst? Mogelijk hadden de voorwerpen een symbolische betekenis. Het is goed denkbaar dat de Guanyin als symbool van genade en troost fungeerde. Immers, in China werd in tijden van gevaar tot haar gebeden. Het plengofferbekertje met de onsterfelijken is bovendien symbool voor voorspoed en een lang leven. Van Buttingha Wichers werd door de Kempeitai, op zoek naar het goud van De Javasche Bank, aan zware verhoren en uithongering onderworpen. $\mathrm{Na}$ een gevangenschap in de Struiswijkgevangenis werd hij overgebracht

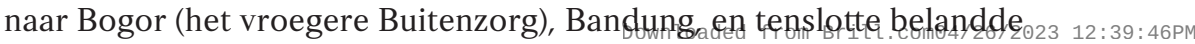


hij in Cimahi (het 'Baroskamp'). Uiteindelijk zou hij terecht komen in het St. Vincentius-kamphospitaal. Ook zijn gezin werd van kamp naar kamp gesleept.

Na de Japanse overgave op I5 augustus 1945, herenigde Van Buttingha Wichers zich in oktober in het Kramatkamp met zijn gezin. Een kleine maand eerder was hij wel al poolshoogte gaan nemen bij de garage met zijn porselein en schilderijen en vond die, zoals hij schreef aan zijn dochter, volledig leeggeroofd terug. Ondanks de luchtige toon van deze brief moet het een grote slag voor hem geweest zijn.

In het relatief veilige kamp verbleef het gezin nog enige tijd in een tweekamerwoning. Achter op het kleine erf met een ligstoel, een tafeltje en twee rotanstoelen presideerde Van Buttingha Wichers op I5 november 1945 de eerste bankenvergadering na de oorlog terwijl de wereld om hem heen in brand stond. Amper twee dagen later overleed hij, verzwakt door de gevolgen van zijn gevangenschap. De poort van het kamp ging slechts even

Afb. 11

De rechter zijkamer voor met boven de tafel een Palembanglamp en in de rechterhoek 'Molukse' stoelen, in de linkerhoek een bureau van ijzerhout open om de lijkauto door te laten. Geen familielid of vriend was daarbij. ${ }^{29}$

Het gezin vertrok als een van de eersten naar Europa. De boeken, verweerd door de kamptijd en het adres van het kamp er nog in geschreven, en de enkele stukken porselein, waaronder de Guanyin en het bekertje met de onsterfelijken, behoorden tot de bagage. Ter herinnering aan Van Buttingha Wichers werd in 1946 in Jakarta een grafmonument onthuld dat inmiddels verloren is.

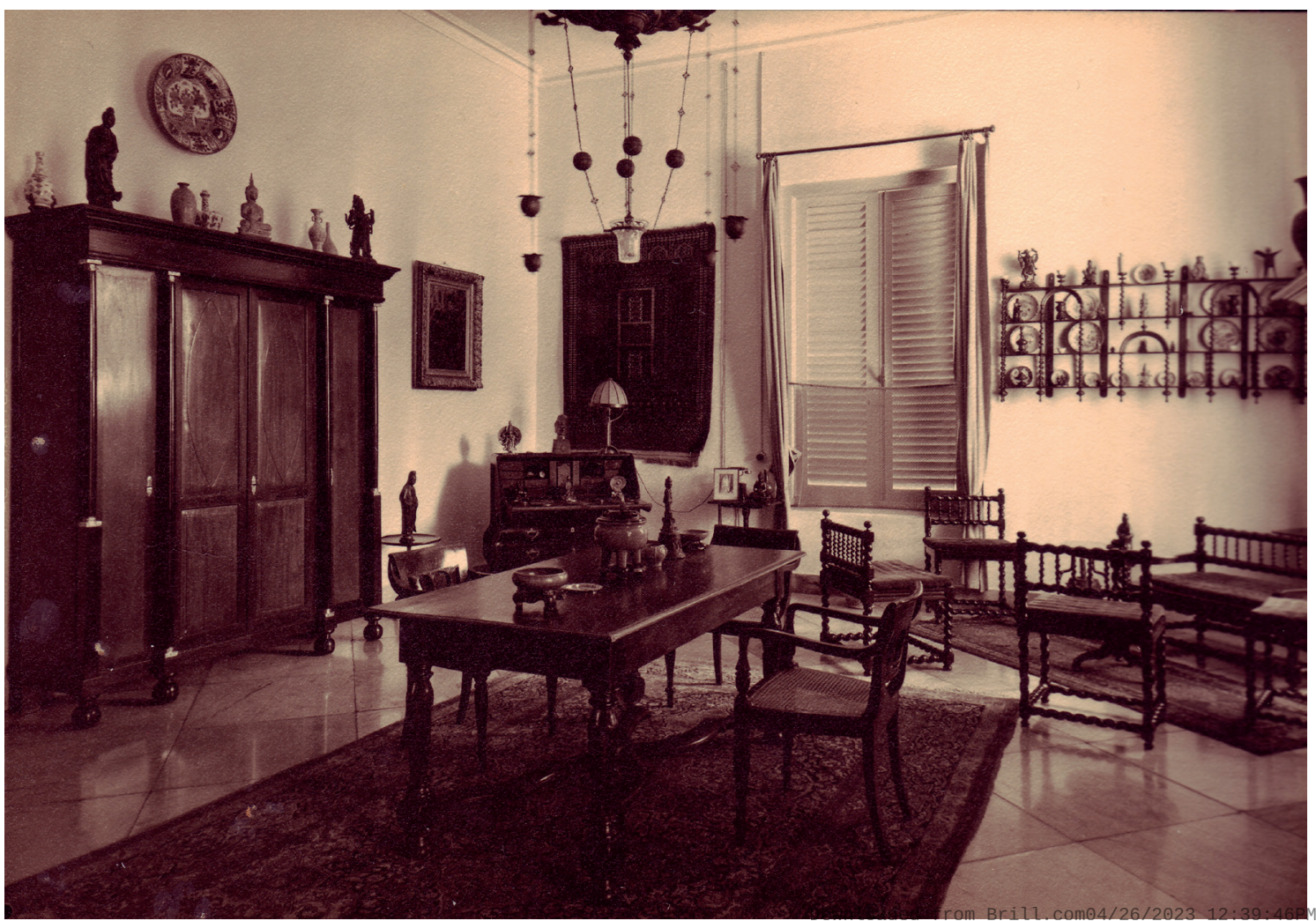


De enkele bewaard gebleven stukken en de boeken riepen samen met de foto's de herinneringen op aan een bijzondere verzamelaar met een liefde voor mooi en divers porselein, aan een voorname bankdirecteur en een verloren echtgenoot en vader. Ze herinnerden het gezin aan de bijzondere tijd die zij in de voorname woning aan het Koningsplein hadden beleefd, maar ook aan de angstige periode die daarop volgde. Deze objecten hielden de herinnering en de betekenis van een weliswaar verloren, maar nooit vergeten periode en collectie in leven.

- Caroline Drieënhuizen is cultuurhistoricus met speciale belangstelling voor de geschiedenis van (koloniaal) Indonesië en materiële cultuur. Zij promoveerde in 2012 op een proefschrift over de Europese koloniale elite in Nederlands-Indië en haar verzamelingen. Zij is als universitair docent verbonden aan de Open Universiteit en als onderzoeker aan de Universiteit van Amsterdam.

- Hans Kristian Ploos van Amstel is kenner van de familiegeschiedenis, beheerder van het archief en schoonzoon van Jettie de la Hayze-van Buttingha Wichers. Hij is hoogleraar en hoofd genoomdiagnostiek aan het UMC Utrecht. Zijn grootvader, jhr. Elisa Ploos van Amstel (I896-I943), was in de beschreven periode president-commissaris van De Javasche Bank.

\section{LITERAT UUR}

Jan van Campen, 'De porseleinverzameling van W.F. van Heukelom', Vormen uit Vuur 208 (2010), pp. 2-12.

De Sumatra Post, 27 mei 1939.

Caroline Drieënhuizen, Koloniale collecties, Europees aanzien. De Europese elite van Nederlands-Indië belicht door haar verzamelingen, I8II-I957, ongepubliceerde dissertatie, Amsterdam, 2012.

Handboek voor Cultuur- en Handelsondernemingen in Nederlandsch-Indië 1939, De Bussy, Amsterdam, 1940.

Jaarboek Koninklijk Bataviaasch Genootschap I948-I95I, Masa Baru, Bandoeng, I95I.

Jaarboek Koninklijk Bataviaasch Genootschap I933, Masa Baru, Bandoeng, 1934

J.J.P. de Jong, De waaier van het fortuin. Van handelscompagnie tot koloniaal imperium. De Nederlanders in Azië en de Indonesische archipel 1595-1950, Sdu, Den Haag, 1998.

G.A. Lamsvelt, 'Een groot Nederlander. In memoriam G. van Buttingha Wichers', Elseviers Weekblad, I november 1947, p. II.

K., In memoriam. Mr. dr. G.G. van Buttingha Wichers 23 februari I879 - I7 november 1945, Amsterdam, I946.

Jeanne Terwen-de Loos, Het Nederlands koloniale meubel, Wever, Franeker, 1985. Jan Veenendaal, Aziatische kunst en de Nederlandse smaak, Gemeentemuseum/ Waanders Uitgeverij, Zwolle, 2014.

Claire Wintle, 'Career development: domestic display as imperial, anthropological and social trophy', Victorian Studies 50 (2008), pp. 279-288.

\section{ARCHIEVEN}

Particulier archief Van Buttingha Wichers, briefje G. van Buttingha Wichers aan dochter Jetteke, d.d. Sint Vincentius, kamphospitaal, Batavia, 22 september 1945.

Koninklijk Instituut voor Taal-, Land- en Volkenkunde (KITLV), Leiden, Archief Henri Titus Damsté, H io84. Inv.nr. 7i. Brief Henri T. Damsté aan familie, d.d. aan boord van de SS 'Van den Bosch', van Surabaya naar Makasar, 26 januari 1904. 
Collectie Nationaal Museum van Wereldculturen (Tropenmuseum), zettels bij inv. nrs. 674-8 (collectie Stammeshaus).

PERSOONLIJKE COMMUNICATIE

Mondelinge informatie van mevrouw Jettie de la Hayze-van Buttingha Wichers.

\section{NOTEN}

* De auteurs zijn Henk Budel erkentelijk voor zijn uitgebreide onderzoek naar dit onderwerp.

I Particulier archief Van Buttingha Wichers: briefje 22 september 1945.

2 Ibid., grafrede dr. R.E. Smits bij onthulling grafmonument Van Buttingha Wichers op Tanah Abang te Batavia, I946.

3 Handboek voor Cultuur- en Handelsondernemingen in Nederlandsch-Indië 1939: II39, II63.

4 Drieënhuizen 2012.

5 Particulier archief Van Buttingha Wichers, stempels op afdrukken van de foto's.

6 Ibid., In Memoriam. Amsterdam 1946. (Het is ondertekend met 'K.'. Mogelijk is de schrijver de afdelingschef van Secretarie, mr. dr. P.F. Kühler.)

7 Ibid.

8 Ibid., brief Van Buttingha Wichers-Laman de Vries aan H. Teunissen, directeur De Javasche Bank, 9 december 1949.

9 Van Campen 20I0: 9.

Io Veenendaal 2014: 22.

II KITLV, H I084. Inv.nr. 7I.

I2 Zettel Nationaal Museum van Wereldculturen inv.nr. TM 674-8.

I3 De Sumatra Post 1939.

I4Zettel Nationaal Museum van Wereldculturen, inv.nr. TM 674-8.

I5 Veenendaal 20I4: 22 en Zettel Nationaal Museum van Wereldculturen, inv.nr.

TM 674-8.

I6 Jaarboek I933: IIO.

I7 Ibid., I37.

I8 Overlevering verhalen door dochter Jettie de la Hayze-van Buttingha Wichers.

I9 Particulier archief Van Buttingha Wichers, tekst van H.H. van Buttingha Wichers-

Laman de Vries op de achterkant van de foto van het betaalmeesterkastje.

20 Wintle 2008: 284.

2I Particulier archief Van Buttingha Wichers, In Memoriam.

22 Overlevering verhalen door dochter Jettie de la Hayze-van Buttingha Wichers.

23 Jaarboek 1948-I95I: 24.

24 Overlevering verhalen door dochter Jettie de la Hayze-van Buttingha Wichers.

25 Ibid.

26 Ibid.

27 De Sumatra Post 1939.

28 Particulier archief Van Buttingha Wichers, tekst van H.H. van Buttingha

Wichers-Laman de Vries op de achterkant van de foto van het

betaalmeesterkastje.

29 Lamsvelt 1947. 